\title{
Foresights, Expectations and Implications of China's Foreign Language Proficiency Scaling and Rating Framework
}

\author{
LIU Xu-liang \\ China Youth University of Political Studies, Beijing, China
}

\begin{abstract}
Referring to the well established foreign language proficiency evaluation scale frameworks such as the CEFR (Common European Framework of Reference for Languages) in Europe and ILR (The Interagency Language Roundtable) scale in the United States, Chinese language education authority is dedicating great efforts to the contruction of the Chinese targeted and tailored national proficiency evaluation system. This initiative will tremendously subvert the traditional language learning and testing mechanism, bring phenomenal transformations and innovations to the future language learning and teaching approaches and methodologies, and meanwhile impose great influence on the language concerning administration and profession.
\end{abstract}

Keywords: China's foreign language proficiency evaluation scale, history and milestones, foresights, expectations and implications, key problems

\section{Introduction}

Under the leadership and promotion of the Ministry of Education, China's foreign language proficiency evaluation scale has long been under construction and prepared to be launched and put into function. Hundreds of experts and scholars from various levels of foreign language instruction committees and more than 20 colleges and universities nationwide are involved in the formulation and completion of this vast project. As a national foreign language ability assessment mechanism especially customized for the Chinese people, its ultimate goal is to promote and facilitate the building of Chinese overall foreign language capacity and meanwhile bring it in line with the world foreign language education trend.

Building a national and universal foreign language proficiency and ability evaluation system is an established task and requirement of China's foreign language education and examination reform. As a new era development strategy and initiative, it will be launched to serve multiple purposes including educational fairness, scientific talent selection, multilateral and mutual learning outcome recognition, as well as lifelong learning mechanism construction.

\section{Background and Horizon}

As early as in September 2014, the State Council promulgated the implementation roadmap of the examination system reform, which has made it clear to strengthen the construction of "foreign language ability evaluation system". One of the key objectives is to develop the Chinese English proficiency scaling and rating framework, which is expected to be able to provide a comprehensive description and evaluation of English

LIU Xu-liang, associate professor, M.A., Foreign Language Department, China Youth University of Political Studies, China. 
learners' language proficiency in well specified levels and help build a unified and universally recognized standard of English proficiency for all kinds of language teaching, learning, judging, and working institutions and individuals at various stages and levels, which consequently will facilitate the communication and mutual recognition of various learning outcomes domestically and globally.

In order to fully implement the reform objective of examination and enrollment set by the State Council, the Ministry of Education has specified that the goal of China's foreign language competence evaluation system is to promote the reform of the present foreign language examinational system in terms of testing contents and models, gradually establish the national English proficiency test system based on the national evaluation standards, and eventually bring it in line with the internationally renowned English test rating scales (LIN, 2015). By 2020, a unified and multi-functional modern foreign language ability evaluation system with the combination of formative (progressive) and summative (terminal) evaluation mechanism is scheduled to be preliminarily completed and established.

To this end, a series of events and conferences dedicated to the designing of the Chinese version of English proficiency scale followed by nine national English proficiency tests are organized and convened by the Ministry of Education. The measurement standard and scale system is expected to be announced to public in 2017 and the grading and testing system will be put into practice by 2020 .

\section{Chronological Milestones in the Framework Construction Process}

\begin{tabular}{|c|c|c|c|}
\hline \multicolumn{2}{|c|}{ Time and duration } & Conferences and events & Achievements and results \\
\hline \multicolumn{2}{|c|}{ October 30-31, 2014} & $\begin{array}{l}\text { A national conference on the National } \\
\text { Foreign Language Competence } \\
\text { Measurement System Construction, i.e., } \\
\text { the overall program development } \\
\text { demonstration conference of the Chinese } \\
\text { English ability scale was held in Beijing. }\end{array}$ & $\begin{array}{l}\text { 1. Proposed to strengthen the foreign language } \\
\text { ability evaluation system construction. } \\
\text { 2. Reached an agreement on the issues of Chinese } \\
\text { English proficiency scale, the development methods } \\
\text { and work steps, etc., and approved the "Chinese } \\
\text { English proficiency scale workbook" in principle. }\end{array}$ \\
\hline \multicolumn{2}{|c|}{ April 27-28, 2015} & $\begin{array}{l}\text { The launch meeting of the National } \\
\text { English Proficiency Scale and Test } \\
\text { Framework construction was held in } \\
\text { Beijing. }\end{array}$ & $\begin{array}{l}\text { A leading group was founded for the construction } \\
\text { and team work and made clear tasks and } \\
\text { responsibilities for each group to ensure authority } \\
\text { and efficiency. }\end{array}$ \\
\hline \multirow{4}{*}{2016} & February 23-27 & $\begin{array}{l}\text { The first formal meeting of the Chinese } \\
\text { English Language Proficiency Scale } \\
\text { construction was convened in Shanghai. }\end{array}$ & $\begin{array}{l}\text { Scale synthesis group and subproject group leaders } \\
\text { convened to cross-examine, analyze, discuss, and } \\
\text { reach consensus on descriptors, then solicited } \\
\text { suggestions from the experts for the language } \\
\text { descriptions, and made preparations for large-scale } \\
\text { grading verification. }\end{array}$ \\
\hline & In June and September & $\begin{array}{l}\text { The first and second training conferences } \\
\text { on the Chinese English Proficiency Scale } \\
\text { rating verification were held in Beijing. }\end{array}$ & $\begin{array}{l}\text { 1. The meetings reviewed the grading and } \\
\text { verification of primary and higher education as well } \\
\text { as the junior high school and vocational colleges. } \\
\text { 2. Members of each sub-project team shared and } \\
\text { discussed their experiences in their respective fields. }\end{array}$ \\
\hline & By October 20 & & $\begin{array}{l}\text { The second stage scale verification work of } \\
\text { collecting data from the teachers and students of } \\
\text { junior and high, secondary and advanced vocational } \\
\text { schools, and continuing education is generally } \\
\text { completed. }\end{array}$ \\
\hline & December 6 & $\begin{array}{l}\text { A memorandum was signed between the } \\
\text { test center and the British Cultural } \\
\text { Education Association. }\end{array}$ & $\begin{array}{l}\text { An important step towards the language proficiency } \\
\text { evaluation communication, cooperation, recognition, } \\
\text { and globalization. }\end{array}$ \\
\hline
\end{tabular}




\section{The Main Tasks and Multi-dimensional and Multifaceted Functions and Values of the Foreign Language Competence Evaluation System}

(1) To stipulate the standards and specifications of different proficiency levels

(2) To determine and judge language proficiency and assess language potential

(3) To offer resources and guidance in language development

(4) To foster peer cooperation and understanding

(5) To encourage personal and professional language development

(6) To support fair selection and professional service

Apart from the top roles of language proficiency measurement and judgment, the platform is supposed to provide extensive language learning and teaching consultancy and training services to both individuals and teaching organizations in areas such as syllabus establishment, curriculum development, teacher training, and academic management. What is more, the program should also provide language education references and professional development guidance for institutions and organizations and offer practical and tailor-made language services to individuals as well as employers.

\section{The Seven Key Language Skills Accessible to Assessment and Evaluation and the Nine Scale Proficiency Framework}

The framework is reportedly consisted of nine grades, with grade one and two roughly corresponding to the level of primary school, grade three to junior high school, grade four to senior high school, grade five and six to university, grade seven to English major, and grade eight and nine corresponding to high-end foreign language talents. Each level has different requirements in the following seven key skills.

(1) Grammatical competence: the knowledge and ability to use the grammatical rules of the language;

(2) Lexical competence: both the knowledge and ability to use lexical items (words, stock phrases, and idiomatic expressions) semantically and pragmatically;

(3) Listening comprehension: the ability to process and understand a spoken message produced either by native or non natives in different contexts and situations;

(4) Spoken competence: the ability to express and articulate both with fluency and accuracy;

(5) Reading comprehension: the ability to understand and handle written texts;

(6) Writing competence: the ability to write in various styles (narratives, expositions, arguments, as well as poetic forms);

(7) Translation skills: the ability to freely convert and maneuver between English and Chinese.

According to the developers, in addition to the description of vocabulary, grammar, listening, speaking, reading, and writing skills, the Chinese English Proficiency Scale has also calculated and involved and generated the sociolinguistic (social relations, expressions of folk-wisdom, dialect and accent) and pragmatic competence indicators (style and register, politeness and euphemism, coherence and cohesion), which aims to objectively and comprehensively describe and measure the overall English language competence, including social and cross-cultural communication effectiveness and appropriateness. The framework also incorporates translation and interpretation capacity scale, which is creative and piloting compared with the foreign scale system counterparts. In comparison, the European Common Language Reference Framework divides learners' general language competence (knowledge, skills, and existential competence) into a six level scale, but it fails 
to develop a "corresponding level test" and is flawed in pragmatic measurement and judgment. Chinese developers ambitiously claim that a nine-level examination system will also be generated in accordance with the scale standards and descriptions which will make the scale system more practical and applicable (JIANG, 2016).

\section{Foresights, Expectations and Implications}

During the past, students at different stages were required to take different English tests (senior high school entrance exam, college entrance exam, band 4 and 6 college English exams, postgraduate entrance exam, public English test 1-4, academic and professional title English exam, etc.). These tests are organized and written by different people with various focuses and emphases due to the gap and inconsistency of the curriculum and syllabus and are only open to people at a required time range. It is physically impossible for language gifted secondary students travelling to colleges to have their language proficiency assessed and tested. As a result, some exams fail to best manifest students' actual language proficiency for the sake of their far excellence over the average. Moreover, some exams are redundant because certain items and contents are overlapped or similar in difficulty (such as the CET6 and postgraduate entrance English exam), thereby may become a waste of time and energy. With this national universal testing framework, people of different ages and at different levels are unanimously and indiscriminately eligible to have their language competence tested either out of request of schooling and employment or merely to meet the needs of their heart and soul. A unified and consistent judging criterion is highly economical and efficient and can greatly reduce the burden and cost of educational staff and resources. Moreover, it provides a well accepted and authoritative language proficiency certificate and reference transcending the educational and professional boundaries. Such an open and easily accessible framework is tremendously conducive to the building of a lifelong learning society. The scale rating system will also make it easier for educational institutions and employers to evaluate the language qualifications of candidates for education admission or employment. And a more universally accepted and recognized language certificate will pave the talents the way to any promising careers either in China or abroad.

The ultimate goal of this project is to foster excellence in language education across China by providing criteria, guidance, and support to teaching institutions and individuals. Other than the obligations and functions of offering language assessment and evaluation criterion and reference, the system is more expected to be able to act as a language learning and teaching support and guidance platform, which is capable of providing practical learning and teaching instructions and resources, offering training and support for those working in the field of modern languages. Therefore, on future platform, students are even supposed to follow an interactive language course at their own pace. They may also have opportunities for collaborative and peer learning with live coaching either in small or broader groups. And users can also set up an online language portfolio based on their own operations and practices to record their language learning experience and achievements and meanwhile to cultivate a habit of learner autonomy and lifelong learning (Council of Europe 2011).

\section{The Key Problems and Issues to be Addressed on the Perspective}

\section{The Establishment of a Fair and Trustworthy Evaluation Platform With Due Credibility and Validity}

To achieve the desired credibility and authority, the following elements are crucial: explicit and precise description of the fundamental concepts such as language proficiency and competence, specification of the criteria for the attainment of a certain level, systematic and professional introductions of the working 
mechanism, and ample evidences of validity, reliability, and fairness. The definition of learner proficiency levels should not be arbitrary but based on a wide range of studies and researches in schools and learner groups, and gives full consideration of the teachers and students' teaching and learning practice in various contexts. Each descriptor and parameter should be clearly termed and defined. The scale of proficiency must be coherent and in a linear measurement like a ruler, on which each level is clearly specified with a clear differentiation from previous and post level and people are capable of making consistent distinctions between them.

\section{A Random Testing Access and Tailor-Made Test Paper}

Currently, foreign language teaching evaluation in China is generally based on standardized tests usually held towards the end of a semester, which belongs to post and summative evaluation. To keep track of the whole process of language development, at least three evaluation methods are to be involved and operated in different stages, namely, the ex-evaluation, the mid-process evaluation, and close-end evaluation. Computer-based adaptive randomization evaluation is highly prioritorized than standardized paper-based evaluation. With this mode, language skills can be strictly specified and graded according to a multitude of indicators and variables. Students take the tests, have instant access to evaluation feedback, and keep well-informed of personal progress after certain toil and effort (LIU, 2016). When taking a test, computers automatically select the test content and stuff according to the candidates' actual language level and ability. Each candidate gets his own test paper with unique and tailor-made content of language item by means of an adaptive and smart methodology and technology. It can effectively avoid the problem of being too difficult or too easy as a whole and reach the purpose of testing each candidate's actual language level and ability. Moreover, computer-based proficiency test can also help to save evaluation results in several separate stages, allowing both teachers and students to keep abreast of their academic progress and adjust their teaching schedule, which is greatly conducive to the implementation of individualized instruction. With the strength of convenient access, individuality, randomness, timely feedback, process monitor and retrieval, and other advantages, this model is replacing the traditional testing mode based on a unified paper and propositions.

\section{Building a Field and Profession Specialized Assessment Framework as an Essential Complement}

The nine level language proficiency rating and testing system is established mainly to test students' general and common English ability rather than specialized English competence such as business English, legal English, medical English and so on. Different fields demand different terminology, expertise, and grammatical patterns. Excellent common English language does not equal to nifty professional language skills and does not guarantee that one can engage in professional research and work in English successfully and satisfyingly. So beside the general English evaluation framework, a complementary field and profession specialized assessment framework is also anticipated and indispensible which will be immensely beneficial and helpful both for the candidates and potential employers with different language requirements in various fields. As a matter of fact, general English competence and professional English competence are complementary and can go in parallel. Sometimes the completion of certain professions (waiters, operators, customs officers) does not take it a necessity and prerequisite to possess a high level general language competence and certificate, instead, only an intermediate or primary or even lower professional language certificate will manage well.

\section{The Establishment of a Private and Secure Evaluation Platform}

Only the participants and the authorized institutions/organizations are entitled to receive and employ the results of the assessments. And no other units and individuals are permitted to access, use, or transmit this 
assessment result and data. Whatever the mark is, the online language assessment shall not be used by any other organizations or individuals other than the participants. It can only be used as an evidence and proof of one's language proficiency at a clearly stated time and moment. Moreover, a well established project is supposed to be able to provide a written feedback as to the strength and weakness of the candidate and where there is a room for further improvements and targeted tips. All the process is based on mutual trust between the test candidate and the project operators and managers. It is the responsibility of the platform to provide participants with the most credible and reliable language assessment to prove that they reach the specific level stipulated on the platform.

\section{Relating School Language Curricula, Textbooks, Approaches and Examinations to the Reference Levels of China's Foreign Language Proficiency Evaluation Scale}

When the Reference Levels of language proficiency is successfully launched and put into effect, all the schools, universities, and training institutes concerned with teaching and testing of languages will seek to relate their curricula, textbooks, approaches, and examinations to the Reference Levels. The educational authorities are responsible to offer certain trainings and organize some workshops to help the language teachers and examiners as well as the curriculum developers, school inspectors, and policy makers to fully understand and get the gist of the testing principles and meanwhile produce and provide some relevant supporting materials including practical tips and exercises. In the meantime, the program developers and language schools should join their efforts to improve and update the language competence evaluation system to ensure it provides employers with solid and convincing reference of language skills in talent selection.

\section{Conclusion}

As a means of promoting education fairness and scientific selection and deepening foreign language teaching and examination reform, the main goal of the foreign language ability evaluation system is to provide a scientific standard and measure for all levels of foreign language teaching and evaluation. As a user-friendly and multi-functional system, it is nation customized but with an international perspective. Beside its role of determining and proving learning achievement and level, it is more expected to become an instructor and facilitator in language learning process. In this sense, China's foreign language ability evaluation scale is not supposed to be a closed, static, and passive evaluation device, instead it should be more like a living guide and coach which can offer feedbacks, instructions, suggestions, and tips. In the final analysis, it will serve as strong linguistic support both for the language learners and all the language concerning policy makers and stakeholders.

\section{References}

China's foreign language proficiency evaluation scale website: http://cse.neea.edu.cn/html1/folder/1505/28-1.htm

Council of Europe. (2011). Common European framework of reference for languages: Learning, teaching, assessment. Modern language division. Strasbourg: Cambridge University Press.

JIANG, G. (2016). Implementing suggestions on deepening the reform of examination and enrolment system and steadily advancing the national assessment system of foreign language proficiency. China Examination, 1, 3-6.

LIN, H. Q. (2015). Deepening the examination and enrollment system reform and strengthening the construction of national foreign language competence evaluation system. China Examination, 1, 3-6.

LIU X. L. (2016). A linguistic perspective of EU's rethinking education program and its implications. Sino-US English Teaching, $13(8), 657-662$.

North, B. (2000). The development of a common reference scale of language proficiency. New York: Peter Lang. 